\title{
EFFECT OF TWO TEACHING METHODS ON SEXUAL HEALTH KNOWLEDGE OF IN-SCHOOL ADOLESCENTS IN ENUGU STATE, NIGERIA
}

\author{
Makata N. E. ${ }^{*}$, Agbapuonwu N.E. ${ }^{1}$, Ilo I.C. ${ }^{1}$, Obasi S.C. ${ }^{2}$, \\ Chinweuba A.U. ${ }^{3}$ and Agu M.C. ${ }^{4}$ \\ ${ }^{1}$ Department of Nursing Science, Nnamdi Azikiwe University, Nnewi Campus, Nnewi \\ ${ }^{2}$ Department of Human Kinetics \& Health Education, Chukwuemeka Odumegwu Ojukwu \\ University, Igbariam Campus \\ ${ }^{3}$ Department of Nursing Sciences, University of Nigeria, Enugu Campus \\ ${ }^{4}$ Department of Environmental Health Science, Nnamdi Azikiwe University, Nnewi Campus \\ *Corresponding Author: ne.makata@ unizik.edu.ng +2348028205942
}

Cite this article:

Makata N.E., Agbapuonwu N.E., Ilo I.C., Obasi S.C., Chinweuba A.U., Agu M.C. (2021), Effect of Two Teaching Methods on Sexual Health Knowledge of InSchool Adolescents in Enugu State, Nigeria. African Journal of Health, Nursing and Midwifery 4(5), 38-48. DOI: 10.52589/AJHNM-

VVSEMFOZ.

\section{Manuscript History \\ Received: 6 July 2021}

Accepted: 4 Aug 2021

Published: 9 Aug 2021

Copyright $\odot 2020$ The Author(s). This is an Open Access article distributed under the terms of Creative Commons AttributionNonCommercial-NoDerivatives 4.0 International (CC BY-NC-ND 4.0 ), which permits anyone to share, use, reproduce and redistribute in any medium, provided the original author and source are credited.
ABSTRACT: This quasi experimental study was designed to determine the effect of lecture and Socratic questioning teaching methods on mean sexual health knowledge gain of in-school adolescents in Enugu State, Nigeria. A sample of 310 senior secondary-two students in eight intact classes were drawn from 16,510 senior in-school adolescents using multi-stage sampling. Sexual health knowledge test comprising 50 items was used to test students' knowledge of sexual health. Student t-test and ANOVA were used to test the hypotheses at $\alpha=0.05$. There was significant difference in the mean sexual health knowledge gain scores of students taught with lecture and Socratic questioning methods (lecture $\bar{x}=9.25>$ Socratic questioning $\bar{x}=7.25 ; p<0.01$ ). There was statistically significant difference in the mean sexual health knowledge gain of students in urban and rural schools $(P<0.001)$. Students in rural areas taught with lecture method had higher mean sexual health knowledge gain score $(\bar{x}=11.75)$ than those in the urban areas $(\bar{x}=7.50)$. Urban subjects taught with Socratic questioning had slightly higher mean sexual health knowledge gain score of $\bar{x}=7.26$ compared to their rural counterparts that scored $\bar{x}=7.25$. Lecture remains effective teaching method for improving sexual health knowledge of students. Health educators should use lecture methods for adolescents' health instructions.

KEYWORDS: In-school Adolescents, Knowledge, Lecture, Rural, Sexual Health, Socratic Questioning, Urban 


\section{INTRODUCTION}

Education is viewed differently based on an individual's philosophies, cultural norms, values, and political inclination. Education, according to Jackson (2007), is the act or process of imparting or acquiring general knowledge, developing the power of reasoning and judgement, and generally preparing oneself or others intellectually for mature life. It is any act or experience that has a formative effect on the mind, character or physical ability. Parankimalil (2012) posited that education is a systematic process through which individuals acquire knowledge, experience, skill, and sound attitudes. Smith (2018) stated that teaching is the process of attending to people's needs, experiences and feelings, and intervening so that they learn particular things, and go beyond the given. Teaching involves creating an environment and engaging with others so that they learn. Kersten (2007) described teaching methods as a system of action, orientations by the teacher to initiate learning acts with the aim of shaping personality traits, which are aimed at achieving competence of action. Teaching methods vary from educator to educator. Ideally, the various methodologies should yield the same results as the students face a common evaluation process. To a large extent, the methods to be used are dependent on the teacher and the level of the class being taught (Ezeani, 2004).

Knowledge is the state or act of knowing, familiarity, awareness or understanding gained through experience or study. According to International Planned Parenthood Federation [IPPF] (2006), knowledge is the sum or range of what has been perceived, discovered or learned, the facts, feelings or experiences known by a person or group of people. Sexual health knowledge (SHK) is viewed as the understanding of facts and information; awareness and familiarity with physical, emotional, mental, physiological, spiritual, legal and societal dimensions of sexuality which encompasses self-esteem, values, choices, and responsibility across the lifespan (Morris, 2007). SHK can be conceptualised as an understanding of facts on the anatomy and physiology of the human reproductive system, processes of reproduction, problems of Human Immunodeficiency Virus (HIV) and Sexually Transmitted Infections/Reproductive Tract Infections (STIs/RTIs), unplanned pregnancy and abortion, infertility and cancer resulting from STIs and sexual dysfunction.

The World Health Organisation (WHO), (2017) stated that adolescence is the period of human growth and development which occurs after childhood and before adulthood, from 10 to 19 years of age. Kumar et al (2017) posited that during this period maximum amount of physical, psychological, emotional and behavioural changes take place. These adolescents' face various health challenges which have been attributed to adolescents' great lack of information and knowledge about the implications of their behaviour on reproductive health as well as the general welfare of the nation (Adepoju, 2005, Sumankuuro et al, 2020). These challenges could be taken care of, by exposing them to human sexuality education. Most often, people may depend on methods of teaching which may not be effective because of modernisation and urbanisation. This could have accounted for several sexual health problems among adolescents. It is as a result of this, that this study has been designed to determine the effectiveness of two methods of teaching sexuality education on sexual health knowledge of in-school adolescents in Enugu State, with a view to determining a more appropriate method of imparting sexual health knowledge among the adolescents.

Literature has shown that there are some methods of teaching that could be more appropriate and effective for teaching human sexuality education. Jaffer, Afifi, Al Ajmi and Alouhaishi (2006) in a cross-sectional survey, using a self-administrated questionnaire examined the 
knowledge, attitudes and practices of Omani adolescents with regard to reproductive health in a nationally representative secondary school. The sample size was 1670 boys and 1675 girls. The respondents were asked questions on puberty, marriage, birth spacing, HIV and AIDS and sexually transmitted infections. The findings showed that half of the respondents knew the changes at puberty of their own sex, while few knew the changes in the opposite sex. Knowledge of fertility period, HIV/AIDS and sexually transmitted infections was poor.

Dube and Sharma (2012) in a study aims at assessing the knowledge, attitude and practice regarding reproductive health among 200 schoolgirls in the age of 15-19 years from rural and urban settings of Jaipur. Results revealed that 40 per cent of rural girls and 60 per cent of urban girls considered menstrual as a natural phenomenon while 39 per cent of urban girls and 56 per cent of rural girls took it as a disease. 11 per cent of urban and 28 per cent of rural girls were not aware of the gap of the periodic menstruation cycle. Differences were evident in the perception of urban and rural respondents regarding the right age of menarche.

McManus and Dhar (2008) in another cross-sectional study in South Delhi, India using a questionnaire to investigate the perception, knowledge and attitude of adolescent urban school girls towards sexually transmitted infections (STIs), HIV and AIDS, safer sex practice and sex education. 251 female students from two senior secondary schools participated in the study. More than one-third of students in the study were found to have no accurate understanding of the signs and symptoms of STIs except that of HIV and AIDS. However, 30\% of respondents reported that HIV and AIDS could be cured, while $49 \%$ felt that condoms should not be available to youths. $41 \%$ of the subjects were confused about whether the contraceptive pill could protect against HIV infection and 32\% thought it should only be taken by married women.

In an experimental study in Dharan town of Nepal by Dhital, Chen, Ahmad, and Stewart, (2005), a structured teaching programme containing information on the human reproductive system was used for the experimental group, while the conventional teaching method was used for the control group. The study population was 200 adolescent school students in four selected schools. The pre-test score of the experimental group on knowledge of reproductive health was $\overline{\mathrm{x}} 39.83(\mathrm{SD} \pm 16.89)$ and of the control group was $\overline{\mathrm{x}} 39.47(\mathrm{SD} \pm 10.08)$. After the intervention, the mean score of the experimental group was (SD84.60 10.60$)$ and of the control was (SD $43.93 \pm 10.08$ ). The researchers concluded that the knowledge on reproductive health and responsible sexual behaviour among school-going adolescents was inadequate. Also, a structured teaching programme was found to be effective in improving the knowledge of adolescents on these issues.

Singh, Garg, Mohapatra and Mishra (2005) using a controlled-intervention study compared the effectiveness of three health educational methods namely lecture, participatory teaching, and written assignment method (pamphlet methods) in disseminating knowledge about HIV and AIDS. 221 subjects were in the intervention groups while 192 subjects were in the control group. The result showed in three intervention group's increase in knowledge was 31.3, 23.6 and $20.3 \%$ for lecture, participatory teaching, and written assignment (pamphlet) groups respectively.

Kang, Greeff and Koen (2008) determined the effect of a comprehensive sexuality education programme on sexual knowledge of adolescents in Busan, Korea using a randomised Solomon four-group design. Two experimental groups and two control groups were selected from two 
different co-educational middle schools. The experimental group was exposed to the sexuality education programme, while the control group received reading matter similar in content to the programme, to reduce the Hawthorne effect. The effect of the programme increased the adolescents' knowledge of sexuality and brought a positive change in their sexual attitudes.

The purpose of this study was to determine the effect of two teaching methods, namely: lecture (didactic) and Socratic questioning on the mean sexual health knowledge gain of in-school adolescents in Enugu State, Nigeria. The lecture method, in this study, is the didactic method of teaching; while the Socratic questioning method of teaching is philosophical inquiry in which the teacher explores the implications of students' positions, stimulates rational thinking and illuminate ideas (Chowdhury, 2008). It primarily involves questioning and critical thinking. Sexual health education in this study included sexual development, reproduction, sexually transmitted infections (STIs), family planning, relationships, communication, and assertiveness. What is sexual health knowledge mean gain scores of students taught with lecture method of teaching? What is sexual health knowledge mean gain scores of students taught with the Socratic questioning method of teaching? What is sexual health knowledge mean gain scores of students taught with a lecture and Socratic questioning methods of teaching in urban and rural schools? To test the effect of the teaching methods, it was hypothesized that: there is no statistically significant difference in the sexual health knowledge mean gain scores of students taught with lecture method and those taught with the Socratic questioning method of teaching; and, there is no statistically significant difference in the sexual health knowledge mean gain scores of students taught with lecture method and those taught with the Socratic questioning method of teaching in urban and rural schools.

The findings of this study to school health educators and other school health practitioners will be beneficial in enhancing teaching and learning outcomes in sexual health education. The result will make them aware of the method that yields better results in teaching human sexuality to secondary school students.

\section{Methods and Materials}

The design used for this study was a quasi-experimental research design because the study sought to establish the effect of lecture and Socratic questioning teaching methods on mean gain sexual health knowledge scores of in-school adolescents. The area of the study was Enugu State, southeast Nigeria with 275 public secondary schools. The study population comprised 16,510 in-school adolescents (State Ministry of Education, 2012). The sample size comprised of 310 SS-2 students in selected intact classes in eight (8) secondary schools in two Education Zones in the State using a simple random sampling technique. The selected intact classes were assigned to treatment with either lecture method or Socratic questioning method in relation to the group their school was in.

Data were collected using researchers developed sexual health knowledge test (SHK-T) consisting of fifty multiple-choice questions sexual health with options A-E. The instrument was validated by five experts. A pilot test was carried and a reliability coefficient of 0.93 was obtained using the Kuder Richardson-21 formula. The SHK-T was used for pre-test and posttest. The pre-test was done to establish the baseline sexual health knowledge of the students, while the post-test was done a week after the intervention to determine the effect of the two teaching methods. The interval between the pre-test and post-test was eight weeks. The eight (8) schools were divided into two groups; then, the lecture method and the Socratic questioning 
method were used respectively for each group of four schools using the two teaching plans for the intervention. The two groups were taught in their classes for an eight minutes double period per week for six weeks. All the students in the selected intact classes were included in the study on the basis that they attended the six teaching-learning sessions. The study was approved by the Human Research Ethics Committee of the Faculty of Health Sciences Nnamdi Azikiwe University Awka. Permission was obtained from the Zonal Inspectors of Education, Principals of the schools and the class teachers of the participating classes. Students were informed about the study and they consented to participate. Participating schools were located far from each other and in different local government areas and thus eliminated the possibility of contamination

The generated data were marked, scored 2 points for each correct response, collated and analysed using Statistical Package for Social Science (SPSS) for version 22. All descriptive statistics were done using frequency, means and standard deviation. The difference in sexual health knowledge mean gain through lecture and Socratic questioning methods was tested using the student t-test, while Analysis of Variance (ANOVA) was used to determine how these vary in urban and rural schools. Scheffe test was used for post hoc multiple comparisons to test differences between and within the groups, where they existed. All inferential statistics were done at a 0.05 level of significance.

\section{RESULTS}

Table 1: Mean sexual health knowledge scores of students taught with lecture and Socratic questioning methods of teaching

\begin{tabular}{lcccccc}
\hline $\begin{array}{l}\text { Teaching } \\
\text { Methods }\end{array}$ & $\mathbf{n}$ & $\begin{array}{c}\text { Pre-test } \\
\overline{\mathbf{x}} \text { score }\end{array}$ & SD & $\begin{array}{c}\text { Post-test } \\
\overline{\mathbf{x}} \text { score }\end{array}$ & SD & $\begin{array}{c}\text { Knowledge gain } \\
\overline{\mathbf{x}} \text { score }\end{array}$ \\
\hline Lecture & 146 & 61.89 & 16.20 & 71.13 & 14.50 & 9.25 \\
$\begin{array}{l}\text { Socratic } \\
\text { questioning }\end{array}$ & 164 & 60.24 & 12.58 & 67.50 & 12.88 & 7.25 \\
\hline
\end{tabular}

Table 1 shows the mean sexual health knowledge scores of students taught with lecture and Socratic questioning teaching method. From the table, students taught with the lecture method had a better post-test mean score of 71.13 than those taught with the Socratic questioning method that had a post-test mean score of 67.50. It also shows that students taught with the lecture method of teaching had better sexual health knowledge mean gain score of 9.25 than their counterparts taught with the Socratic questioning method that had a mean gain score of 7.25 . 
Table 2: t-test summary of sexual health knowledge mean gain scores of students taught with lecture and Socratic questioning teaching methods

\begin{tabular}{lcccccc}
\hline $\begin{array}{l}\text { Teaching } \\
\text { Methods }\end{array}$ & $\mathbf{n}$ & $\overline{\mathbf{x}}$ & SD & df & t-value & P-value \\
\hline Lecture & 146 & 9.25 & 7.54 & & & \\
& & & & 308 & 2.68 & $0.008^{*}$ \\
Socratic questioning & 164 & 7.25 & 5.44 & & & \\
\hline * Significant & & & & &
\end{tabular}

In table 2, t-value is 2.68 , and $\mathrm{P}$-value is 0.008 . Independent sample $\mathrm{t}$-test indicated a significant difference $(\mathrm{P}<0.01)$ in sexual health knowledge mean gain scores of students between the two teaching methods. The sexual health knowledge mean gain score for the lecture method group was higher $(\overline{\mathrm{x}}=9.25)$ compared with the Socratic questioning method $(\overline{\mathrm{x}}=7.25)$. The hypothesis is therefore rejected.

Table 3: Mean sexual health knowledge scores of students taught with lecture method of teaching according to school location

\begin{tabular}{lcccccc}
\hline Location & $\mathbf{n}$ & $\begin{array}{c}\text { Pre-test } \\
\overline{\mathbf{x}} \text { score }\end{array}$ & SD & $\begin{array}{c}\text { Post-test } \\
\overline{\mathbf{x}} \text { score }\end{array}$ & SD & $\begin{array}{c}\text { Knowledge gain } \\
\overline{\mathbf{x}} \text { score }\end{array}$ \\
\hline Lecture & 86 & 69.03 & 11.05 & 76.53 & 8.63 & 7.50 \\
Socratic questioning & 60 & 51.65 & 16.97 & 63.40 & 17.52 & 11.75 \\
\hline
\end{tabular}

Table 3 shows the mean sexual health knowledge scores of students taught with lecture method of teaching according to the location of their schools. The table shows that the urban students had a better post-test mean score of 76.53 and an SD of 8.63 It also shows that rural students had a better sexual health knowledge mean gain score of 11.75 than their urban counterparts that had a mean gain score of 7.50.

Table 4: Mean sexual health knowledge scores of students taught with the Socratic questioning method of teaching according to school location

\begin{tabular}{lcccccc}
\hline Location & $\mathbf{n}$ & $\begin{array}{c}\text { Pre-test } \\
\overline{\mathbf{x}} \text { score }\end{array}$ & SD & $\begin{array}{c}\text { Post-test } \\
\overline{\mathbf{x}} \text { score }\end{array}$ & SD & $\begin{array}{c}\text { Knowledge } \\
\text { gain } \\
\overline{\mathbf{x}} \text { score }\end{array}$ \\
\hline Urban & 65 & 66.83 & 10.25 & 74.09 & 10.08 & 7.26 \\
Rural & 99 & 55.92 & 12.13 & 63.17 & 12.72 & 7.25 \\
\hline
\end{tabular}

Table 4 presents the mean sexual health knowledge scores of students taught with the Socratic questioning method of teaching according to the location of schools. The table shows that the urban students had a better post-test mean score of 74.09 and an SD of 10.08 than their rural counterparts who scored a mean of 63.17 and an SD of 12.72. Also, the urban subjects had a slightly higher sexual health knowledge mean gain score of 7.26 than their rural counterparts that had a mean gain score of 7.25. 
Table 5: ANOVA summary of the analysis of sexual health knowledge mean gain scores of students in urban and rural schools according to teaching methods

\begin{tabular}{lccccc}
\hline $\begin{array}{l}\text { Source of } \\
\text { Variation }\end{array}$ & $\begin{array}{c}\text { Sum of } \\
\text { Squares }\end{array}$ & $\begin{array}{c}\text { Mean } \\
\text { Squares }\end{array}$ & df & F-ratio & P-value \\
\hline Between groups & 944.39 & 314.39 & 3 & & \\
Within groups & 12453.99 & 40.69 & 306 & 7.73 & $<0.001 *$ \\
Total & 13398.38 & & 309 & & \\
\hline
\end{tabular}

* Significant

Table 5 shows the ANOVA summary of the analysis of data done to test this hypothesis. The result shows that the F-calculated value is 7.73. ANOVA test indicated significant differences $(\mathrm{P}<0.001)$ in sexual health knowledge mean gain scores among the urban and rural students taught with a lecture and Socratic questioning methods of the teaching. Hypothesis three is therefore rejected.

Table 6: Post-hoc multiple comparison test for methods of teaching and location of schools

\begin{tabular}{lccccc}
\hline Cross-tabulated & & \multicolumn{2}{c}{ Lecture } & \multicolumn{2}{c}{ Socratic questioning } \\
\cline { 3 - 6 } teaching methods & & Urban & Rural & Urban & Rural \\
\hline Lecture & Urban & - & $.002^{*}$ & .997 & .995 \\
& Rural & $.002^{*}$ & - & $.002^{*}$ & $.001^{*}$ \\
Socratic questioning & Urban & .997 & $.002^{*}$ & - & 1.00 \\
& Rural & .995 & $.001^{*}$ & 1.00 & - \\
\hline
\end{tabular}

* Significant

In table 6, a post hoc multiple comparison (Scheffe test) analysis further indicated that rural students taught with lecture, had significantly higher sexual health knowledge mean gain score compared with the urban students taught with a lecture $(\mathrm{P}<0.01)$, urban students taught with Socratic method $(\mathrm{P}<0.01)$ and those of rural students taught with Socratic method $(\mathrm{P}<0.001)$ respectively. Other regimens were compared showed no significant differences.

\section{DISCUSSIONS}

Students taught with the lecture method had a better knowledge gain than their counterparts taught with the Socratic questioning method. The difference in the sexual health knowledge gain in these two teaching methods was found to be significant. This finding reflects the popular use of lecture/discussion as a generic method of teaching and instruction in schools including secondary schools. Thus, the adolescents might have become very conversant with it in teaching-learning experiences compared with the Socratic questioning method which may not be in common use by health instructors. Students were not ignorant of the Socratic questioning strategy as they are used from time to time in health instruction and the researchers did not observe differences in students' responses during the teaching-learning experiences. 
The result is similar to the findings of Dhital, et al (2005) where the mean of the experimental group on knowledge of reproductive health was higher than that of the control group. Also Singh, et al (2005) observed that lecture was the most effective in increasing knowledge when compared with participatory teaching and written assignment (pamphlet) groups respectively. This might be related to the lecture being the teaching method predominant employed by teachers in a good number of students instruction. Van der Geugten, van Meijel, den Uyl, and de Vries, (2015) noted in their study that SRH intervention led to a small but significant increase in the students' knowledge. Andargie, et al (2007) also reported that students had adequate knowledge about HIV and AIDS and VCT. Anderson and Beutel (2007) showed that nearly everyone could name at least one method of preventing HIV infection. Kang, et al (2008), also observed that the effect of the programme increased the adolescents' knowledge of sexuality in their study group. These findings are at variance with the result of MacManus and Dhar (2008) who showed that more than one-third of students in their study had no accurate understanding about the signs and symptoms of STIs except that of HIV and AIDS, $41 \%$ were confused about whether the contraceptive pill could protect against HIV infection. Also, Jaffer, et al (2006) observed that their subjects' knowledge of fertility period, HIV and AIDS and sexually transmitted infections was poor.

The rural students taught with the lecture method had better sexual health knowledge mean gain score of 11.75 than their urban counterparts that had a mean gain score of 7.50. Also, urban subjects taught with the Socratic questioning method had a slightly higher sexual health knowledge mean gain score of 7.26 compared to their rural counterparts that scored 7.25. This finding was also statistically significant between urban and rural schools $(\mathrm{P}<0.001)$. The findings were surprising as the students were in the same class, used the same curriculum and were exposed to the same intervention. This difference might be a result of variation of stimuli outside the school setting such as alternative sources of information and the environment which could influence their knowledge. On another note, the intervention might also have been a motivating factor for some of the students to study more about human sexuality outside the school set-up. Similarly, Nwaorgu, et al (2008) observed that there was a significant difference $(\mathrm{p}<0.0001)$ in the proportion of the rural residents when compared with their urban counterparts that could correctly identify the wrong ideas about human reproduction. Dube and Sharma (2012) also observed a difference in knowledge of reproductive health among rural and urban respondents in their study. These findings are at variance with the result Rondini and Krugu (2009) which showed a low familiarity of the student population with family planning methods, HIV and AIDS transmission. They inferred that poor infrastructures and low accessibility of the rural areas in Northern Ghana might have led to uneven distribution of reproductive health education programmes. Arguably family planning methods are the aspect of sexual health adolescents might not be adequately exposed to due to the norm of preaching abstinence until married and thus these misconceptions could affect students interest and access to such information and thus affect the extent of knowledge gained. These variations could also be to the scope of coverage of subject matter during the teaching-learning experiences of the students. In this study, the six-week duration of teaching and learning might have given the students the opportunity for gaining a wide range of information on human sexuality and sexual health which could have predicted our findings. 


\section{CONCLUSIONS}

Findings of this study revealed that students taught with lecture method group had significantly higher sexual health knowledge mean gain scores. The lecture method of teaching remains an effective teaching and health education method for improving sexual health knowledge of students than the Socratic questioning method of teaching with a statistically significant difference. The rural students taught with lecture method had better sexual health knowledge mean gain score than their urban counterparts Also urban subjects taught with the Socratic questioning method had a slightly higher sexual health knowledge mean gain score compared to their rural counterparts. This finding was also statistically significant between urban and rural schools.

\section{RECOMMENDATION}

The glaring difference shown in this study where the lecture was found to be more effective in improving adolescents' sexual health knowledge scores in the state implies that lecture should be used as a teaching strategy for health instruction to improve students' sexual health knowledge in our schools. More so, other appropriate and innovative teaching methods could be explored to assess their efficacy as a teaching-learning strategy for health instruction of these students to improve their sexual health knowledge. Educational efforts should be focused on these adolescents. Also, out of school adolescents and adults should not be neglected.

\section{Acknowledgements}

We thank the Zonal Inspector of Education and his staff for their contributions to the success of this study.

Funding: No funding sources

Conflict of interest: None

Ethical approval: The study was approved by the Human Research Ethics Committee of the Faculty of Health Sciences Nnamdi Azikiwe University Awka

\section{REFERENCES}

Adepoju, A. (2005). Sexuality education in Nigeria: Evolution challenges and progress. Understanding Human sexuality 3, Lagos: African Regional Sexuality Resource Centre Andargie, G., Kassu, A., Moges, F., Kebede, Y., Gedefaw, M., Wale, F., Alem, A., Andualem, B., Adungna, S. (2007). Low prevalence of HIV infection and knowledge, attitude and practice on HIV/AIDS among high school students in Gondar, Northwest Ethiopia. Ethiopian Journal of Health Development. 21 (2), 179-182

Anderson, K. G., Beutel, A. M. (2007). HIV/AIDS prevention Knowledge among youths in Cape Town. South African Journal of Social Science, 3(3), 143-151

Chowdhury, F.M. (2008). Tutorial Dialogue Advance Dialogue Modelling for practical application. Retrieved from http://www.castutoring.neu.edu/tutoring_services/tytpoes_tutoring/AApplicatio'08-09 
Dhital, A.D., Badhu, B.O., Paudel, R.K. (2005). Effectiveness of structured teaching program in improving knowledge and attitudes of school-going adolescent on reproductive health Kathmandu University Medi8cal Journal3 (4), 12 380-383 Retrieved from http://www.nchi.nlm.nih.gov/pubmed/16449840

Dube S., \& Sharma K. (2012) Knowledge, Attitude and Practice Regarding Reproductive Health among Urban and Rural Girls: A Comparative Study. Studies on Ethno-Med. 6(2), 85-94. Retrieved from DOI: 10.1080/09735070.2012.11886424

Ezeani, L. U. (2004). Principles and Methods of Teaching. ( $2^{\text {nd }}$ Ed.). Onitsha: West and Solomon.

http://www.helium.com/items/583911-the-definition-of-education.

International Planned Parenthood Federation [IPPF]. (2006). IPPF Framework for Comprehensive Sexuality Education. London: Author

Jackson, S. (2007). Definition of Education. Retrieved from

Jaffer, Y.A., Afifi, M., Al Ajmi, F., \&Alouhaishi, K. (2006). Knowledge, attitudes and practices of secondary-school pupils in Oman: II. Reproductive health. La Revue de Santé de la Méditerranée orientale, 12, (1/2),

Kang, H., Greeff, M., \& Koen, M. (2008). The Influence of sexuality education on the sexual knowledge and attitudes of adolescents in Busan, Korea. The Journal of Curriculum and Evaluation, 11(2), 189-210.

Kersten, S. (2007). The Term Teaching Methods. Retrieved from www.thetermteachingmethods.pdf.

Kumar, R., Goyal, A., Singh, P., Bhardwaj, A., Mittal, and Yadav, S. S. (2017) Knowledge Attitude and Perception of Sex Education among School Going Adolescents in Ambala District, Haryana, India: A Cross-Sectional Study J Clin Diagn Res. 11(3), LC01LC04.. doi: [10.7860/JCDR/2017/19290.9338]

McManus, A., \& Dhar, L. (2008). Study of knowledge, perception and attitude of adolescent girls towards STIs/HIV, safer sex and sex education: (A cross-sectional survey of urban adolescent school girls in South Delhi, India) BMC Women's Health.

8:12doi:10.1186/1472-6874-8- 12. Retrieved from https://www.biomedcentral.com/1472-6874/8/12

Morris, J F. (2007). "Between knowledge and practice: Factors that influence the operationalisation of sexual health knowledge in African American female college students". Theses and Dissertations. Paper 2294. Retrieved from http://scholarcommons.usf.edu/etd/2294

Nwaorgu, O. C., Onyeneho, N. G., Okolo, M., Obadike, E., \& Enibe, G. (2008). Reproductive health knowledge and practices among junior secondary school grade one students in Enugu State: Threat to achieving Millennium Development Goals in Nigeria. East African Journal of Public Health, 5(2), retrieved from https://www.bioline.org.br/pdf?lp08024.

Parankimalil, J. (2012). Meaning, Nature and Aims of Education. Retrieved from, https://johnparankimalil.wordpress.com/.../meaning-nature-and-aims-of-education

Singh, S. P., Garg, N., Mohapatra, S. C., \& Mishra, R. N. (2005).Effect of some HIV / AIDS education among adolescent students Indian Journal of Community Medicine, 30 (1), (2005-03-2005-03.)

Smith, M. K. (2018). 'What is teaching?' in The encyclopaedia of pedagogy and informal education. Retrieved: $8^{\text {th }}$ June 2020 from[https://infed.org/mobi/what-is-teaching/. 
State Ministry of Education (2012) Post Primary Education Management Board: School Statistics by Letter Head. Enugu: PPSMB.

Sumankuuro, J., Asuuri, A., Mikare, M., Ngmenkpieo, F., Crockett, J. \& Wulifan, J. (2020) High School Student's Knowledge, Attitude and Participation in Sexual Health Education in Rural Northern Ghana. Journal of Biosciences and Medicines, 8, 64-83. doi: $10.4236 / \mathrm{jbm} .2020 .85007$.

Van der Geugten, J., van Meijel, B,. den Uyl , M.H.G, \& de Vries, N.K. (2015). Evaluation of a Sexual and Reproductive Health Education Programme: Students' Knowledge, Attitude and Behaviour in Bolgatanga Municipality, Northern Ghana African Journal of Reproductive Health 19 (3), 126-136

World Health Organization (WHO) (2017). Adolescent development. Retrieved from: http://www.who.int/maternal_c hild_adolescent/topics/adolescence/dev/en/ 